\title{
Clarity and Challenges in Tissue Fibrosis
}

\author{
Scott L. Friedman
}

\begin{abstract}
The tremendous progress in understanding the mechanisms of tissue fibrosis has led to realistic hopes for effective antifibrotic therapies in a range of diseases, including hepatic fibrosis, idiopathic pulmonary fibrosis, and renal fibrosis, as well as fibrotic disorders of muscle, heart, skin and bone marrow. Common mechanisms across these different tissues have unearthed targets that may be relevant to many organs. Best understood are pathways leading to hepatic fibrosis, which also predispose to hepatocellular carcinoma. Hepatic stellate cells are the principal fibrogenic cells in the liver following their activation into myofibroblasts, and their detailed characterization has unearthed many targets for therapy. Increasingly, investigators now rely on genetic mouse models to define contributions of specific molecules, in hopes of antagonizing these molecules as therapeutic targets. Both genomic and molecular approaches are unveiling new patterns of gene expression and molecules. A robust framework for antifibrotic drug discovery has been developed, and many agents are in clinical trials. With iterative evaluation of drug candidates in both animal models and humans, accelerated progress in bringing these drugs to patients is anticipated.
\end{abstract}

Keywords Hepatic fibrosis • Stellate cells • Antifibrotic • Cirrhosis • Pulmonary fibrosis $\bullet$ Autophagy $\bullet$ Fibrogenesis $\bullet$ Macrophages

\section{Introduction}

The topic of tissue fibrosis has become increasingly important in clinical medicine with the realization that up to $45 \%$ of all deaths in the industrialized world are due to fibrotic diseases of various organs [1]. Great strides have been made in understanding the cellular basis, molecular mechanisms, and both tissue specific and generalized features of fibrosis across organs.

Generally, fibrosis mechanisms are similar across different tissues, including the heart, lung, liver, pancreas, kidney, bone marrow, CNS, and skin, among others [2].

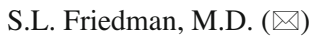

Division of Liver Diseases, Icahn School of Medicine at Mount Sinai,

1425 Madison Ave., Room 11-70C, New York, NY, Box 1123 10029-6574, USA

e-mail: Scott.Friedman@mssm.edu 
In each case, common events include injury to epithelial tissues that leads to activation of resident mesenchymal cells, or myofibroblasts. While the mechanisms of fibrogenesis are similar, the likelihood of regeneration and regression varies widely across organs. Also highly variable is the underlying regenerative capacity of each organ, with the liver being most regenerative and the lung showing the least capacity for tissue regeneration. Ongoing epithelial injury typically tips the balance toward progressive fibrosis rather than regression, yet the factors underlying this critical balance are not well understood.

\section{Liver Fibrosis}

\section{Mechanisms}

In the liver, fibrosis is a common pathway among many different etiologies, including viral hepatitis B and C, nonalcoholic steatohepatitis, and alcoholic liver disease, as well as inherited metabolic disorders, drug-induced liver injury, immune disorders, and neonatal cholestatic syndromes [3]. As noted above, the liver is relatively unique in the long duration of fibrosis, such that, typically, chronic injury must persist for decades before advanced fibrosis, also known as cirrhosis, develops. Once cirrhosis is present, however, the liver harbors a dramatically increased risk of hepatocellular carcinoma (HCC), which currently has the fastest rising tumor incidence in the world [4]. Moreover, HCC is the second leading cause of cancer mortality worldwide, yet curative therapies are rarely available unless aggressive screening methods are used to detect small tumors that are resectable or amenable to local tissue ablation.

The mechanisms of fibrosis in the liver have been greatly clarified thanks to the development decades ago of methods to isolate and grow the primary fibrogenic cells in the liver, the hepatic stellate cells. The cell type is a resident pericyte, which has the unusual feature of storing large amounts of vitamin A, or retinoids, in perinuclear cytoplasmic droplets [5]. Thus, this cell type is the primary storage depot for retinoids in the body. Following injury, hepatic stellate cells undergo a very characteristic activation, or trans-differentiation, yielding a highly fibrogenic and contractile cell. During this process, they release retinoids and acquire more prominent contractile filaments, as well as a whole range of new features that collectively can be considered a "conspiracy to make a scar". This activation includes upregulation of energetic receptors, increased pro-inflammatory and profibrogenic cytokines, and increased signals that promote cell survival.

More recently, additional subtle features of stellate cell activation and liver fibrosis have been uncovered. Prominent among these is an increasingly nuanced appreciation for inflammatory cell subset composition that changes from normal to injured liver, including different types of NK cells, NKT cells, and other lymphocyte subsets, as well as alterations in macrophage composition [6, 7]. Additionally, there has been increasing appreciation for the contribution of adipokines to fibrosis 
progression and regression [8, 9]. In general, adiponectin is considered antiinflammatory and antifibrotic, whereas leptin is pro-inflammatory and fibrogenic. Additional adipokines are under study, and their relevance to human disease has been heightened by the growing epidemic of nonalcoholic fatty liver disease, [10] which promises to dwarf the public health impact of viral hepatitis in the USA and Europe, and possibly Asia [11].

Another important development has been the discovery that activated hepatic stellate cells can revert to an inactivated phenotype when liver injury resolves [1214]. Previously, apoptosis had been the major mechanism invoked to account for loss of activated stellate cells when fibrosis regresses [15]. However, now that reversion to an inactivated state has been validated in animal models, this indicates that there is a reservoir of cells that can both activate and then de-activate. Moreover, the activated cells are distinct from truly quiescent stellate cells in their capacity to re-activate more briskly.

\section{Role of Autophagy}

Our studies have recently focused on a vital intracellular pathway known as autophagy [16] and its contribution to hepatic stellate cell activation. The work was spurred by a seminal observation reported by Czaja and colleagues in 2009 [17], demonstrating that hepatocytes utilize autophagy to provide intracellular energy when stressed, through hydrolysis of intracellular lipids. This raised the interesting prospect that stellate cells, which are "professional" lipid-storing cells, might also exploit autophagy to metabolize intracellular lipids. We addressed this prospect by inhibiting autophagy either chemically or genetically in hepatic stellate cells to assess the impact on stellate cell activation [18]. Through a variety of methods, our data clearly indicated that autophagy of stellate cells is required to provide shortterm but vital intracellular energy as the cell undergoes the highly energy intensive process of activation. Moreover, the block in stellate cell activation conferred by autophagy inhibition could be overcome if the cells were provided exogenous energy in the form of oleic acid, a monounsaturated omega- 9 fatty acid.

Of broader significance, our work demonstrated that autophagy is equally vital to fibrogenesis in mesenchymal cells from other tissues as well. Specifically, embryonic fibroblasts from mice genetically lacking Atg5, a key autophagy regulatory protein, have reduced expression of collagen I, beta-PDGF receptor, alpha smooth muscle actin, and matrix metalloproteinase-2 [18]. Similarly, blocking autophagy in mouse mesangial cells and human pulmonary fibroblasts yielded similar antagonism of fibrogenic properties.

Taken together, these findings implicate autophagy in a new context in which the pathway is essential for energy production in cellular fibrosis. While a simplistic interpretation would be that autophagy blockade could lead to decreased fibrosis, in reality autophagy is an essential pathway for the homeostasis of epithelial cells, and many animal models demonstrate that blocking autophagy in these cells is 
deleterious to organ function. Therefore, any therapeutic exploitation of autophagy inhibition would need to be highly targeted only to fibrogenic cells and not affect surrounding epithelia or other cell types.

\section{Genetic Models of Liver Fibrosis}

In more recent studies, we have begun using genetic models to explore other features of stellate cell activation and biology. We recently developed a mouse model in which stellate cells can be selectively ablated [19]. The model utilizes transgenic expression of the herpes simplex thymidylate kinase gene, which, when expressed in proliferating cells, renders them susceptible to killing by the antiviral drug ganciclovir. To perform these studies, induction of liver injury was required in order to provoke stellate cell proliferation so they would be susceptible to killing. As expected, depletion of stellate cells led to reduced fibrosis and diminished expression of stellate cell activation markers, both following carbon tetrachloride or duct ligation models of injury and fibrosis. We also analyzed inflammatory gene expression and specifically detected increased hepatic expression of interleukin-10 and interferon-gamma following depletion. These results reinforce the central role of stellate cells in liver fibrosis, but also highlight its contribution to modifying the inflammatory milieu in liver injury.

\section{Reversibility of Hepatic Fibrosis}

Among the most exciting discoveries has been the recognition that hepatic fibrosis and even cirrhosis are reversible. While animal studies supported this conclusion for many years, there is now strong human evidence for fibrosis regression. The evidence is clearest in patients who have either complete suppression of hepatitis $\mathrm{B}$ or cured hepatitis $C[20,21]$. In each circumstance, removing active viral infection leads to substantial fibrosis regression and restoration of normal architecture, even in a majority of cirrhotic patients.

The mechanisms underlying fibrosis reversibility represent a fertile avenue for uncovering targets whose manipulation could accelerate fibrosis regression in human disease, even when the primary etiology is not controlled-for example, nonalcoholic steatohepatitis. In the liver, increasing evidence implicates subsets of hepatic 'LY6C-lo' macrophages as harboring a fibrolytic profile that contributes to matrix degradation when liver injury subsides [22]. Therapeutic efforts to exploit this finding include cytokine therapies that could amplify subpopulations of fibrolytic macrophages, or even ex vivo cell differentiation using genetic techniques, followed by re-infusion of fibrolytic cells. There are, however, other pathways of 
matrix degradation, whose quantitative contribution to fibrosis regression in vivo are not completely clarified. For example, dendritic cells secrete MMP-9 [23], whereas neutrophils secrete MMP-8. Further clarification of the mechanisms underlying fibrosis regression are likely to emerge with continued use of more refined genetic mouse models, combined with the ability to analyze in detail the features of fibrosis regression in human liver disease [24]. The latter prospect is especially attractive with the availability of direct-acting antivirals for hepatitis $\mathrm{C}$, which promise to cure disease in greater than $90 \%$ of patients with fewer side effects then previous interferon-based therapies [25, 26]. Thus, with more patients who have advanced fibrosis achieving an HCV cure, it will be highly informative to analyze liver tissues in order to characterize those features that contribute to fibrosis regression in human disease.

\section{Genomics of Fibrosis}

With the era of "big data" upon us, we are now using genomic methods to evaluate large data sets in hopes of uncovering unique and important antifibrotic drug targets. Several databases exist in which gene expression patterns in response to known drugs can be interrogated for different cell types, including mesenchymal cells [27]. Using this approach, we seek to identify stellate cell-specific genes whose antagonism could yield an antifibrotic effect. Antagonism could be achieved using either neutralizing antibodies, siRNAs, or small molecules. The regulatory paths for approval for such agents are yet to be clarified, but there is intense activity in the drug development world, in partnership with the FDA, to accelerate the development of clinical trial designs that can shorten drug testing and bring effective therapies to patients with fibrotic diseases more quickly.

From a clinical perspective, there are important lessons about development and testing of antifibrotic drugs acquired from years of testing agents for idiopathic pulmonary fibrosis $[2,28,29]$. The contrast to hepatic fibrosis is interesting, in that pulmonary fibrosis is a catastrophic illness with a median survival of 3 years, in contrast to the slow progress of hepatic fibrosis. In part, this poor prognosis has driven more aggressive efforts to test and approve antifibrotic drugs faster. Partly as a result of this more extensive trial experience, pulmonary fibrosis trials are now underpinned by well-validated functional tests, whose improvement is acceptable to regulatory agencies as an indication of drug efficacy. Moreover, methods have been developed to sample bronchoalveolar lavage macrophages as biosensors of drug efficacy and some specific trials have sought to antagonize TGF-beta activation. Studies of liver fibrosis will benefit from lessons learned in the pulmonary field, and drugs proven effective in the latter group may be equally valuable to patients with chronic liver disease who are at risk for cirrhosis. 


\section{Framework for Antifibrotic Therapies}

A framework for organizing our understanding of potential antifibrotic therapy delivery is well established. The first principle is to determine if a particular pathway or target is a "core" or "regulatory" one [30]. Core pathways are typically common to two or more tissues and species, are essential for fibrosis, and are presumed to have an earlier evolutionary role. In contrast, a regulatory pathway might be one that is more tissue specific and therefore less likely to elicit off-target effects following its antagonism in a clinical setting. A recent example of an ideal core pathway is alphaV integrin, based on studies by Henderson et al. [31], which demonstrated that this pathway is critical to driving fibrosis in several tissues. Moreover, development of small-molecule antagonists to this integrin are well underway and represent a drug development path that has already been well established for other disease indications [32].

The point of attack for fibrosis therapies and liver include: (1) reducing the primary disease - for example, antivirals or abstinence from alcohol, among others; (2) reducing tissue injury and fostering epithelial repair through the use of epithelial protectants, anti-inflammatory agents, or modulation of inflammatory cell subsets, as described above; (3) blocking myofibroblast proliferation, angiogenesis, or contractility, using specific cytokine receptor antagonists; (4) promoting apoptosis of activated myofibroblasts; (5) stimulating metalloproteinase activity, either through induction of these enzymes or through antagonism of their natural inhibitors specifically, tissue inhibitors of metalloproteinases. A detailed description of the agents in these different categories is beyond the scope of this review, but the reader is referred to several articles [33-35].

\section{Summary}

There are four major conclusions of this work:

1. Tissue fibrosis mechanisms are sufficiently clarified to expect progress in developing and testing antifibrotic drugs.

2. While most mechanisms of fibrosis are shared across organs, each site or tissue presents unique challenges to drug development and clinical trial design.

3. Clinical trial development will require robust, validated endpoints that correlate with clinical outcomes.

4. We are reaching a "tipping point" of interest and emerging clinical trials that will establish proof of principal for antifibrotic drugs.

Open Access This chapter is distributed under the terms of the Creative Commons Attribution Noncommercial License, which permits any noncommercial use, distribution, and reproduction in any medium, provided the original author(s) and source are credited. 


\section{References}

1. Wynn TA (2008) Cellular and molecular mechanisms of fibrosis. J Pathol 214(2):199-210

2. Friedman SL, Sheppard D, Duffield JS, Violette S (2013) Therapy for fibrotic diseases: nearing the starting line. Sci Transl Med 5(167):167sr161. doi:10.1126/scitranslmed.3004700

3. Kocabayoglu P, Friedman SL (2013) Cellular basis of hepatic fibrosis and its role in inflammation and cancer. Front Biosci (Sch Edit) 5:217-230. doi:S368 [pii]

4. Villanueva A, Hernandez-Gea V, Llovet JM (2012) Medical therapies for hepatocellular carcinoma: a critical view of the evidence. Nat Rev Gastroenterol Hepatol 10(1):34-42. doi:nrgastro.2012.199 [pii] 10.1038/nrgastro.2012.199

5. Friedman SL (2008) Hepatic stellate cells - protean, multifunctional, and enigmatic cells of the liver. Physiol Rev 88(1):125-172

6. Gao B, Radaeva S (2013) Natural killer and natural killer T cells in liver fibrosis. Biochim Biophys Acta 1832(7):1061-1069. doi:10.1016/j.bbadis.2012.09.008

7. Iredale JP, Thompson A, Henderson NC (2013) Extracellular matrix degradation in liver fibrosis: biochemistry and regulation. Biochim Biophys Acta 1832(7):876-883. doi:10.1016/j. bbadis.2012.11.002

8. Handy JA, Fu PP, Kumar P, Mells JE, Sharma S, Saxena NK, Anania FA (2011) Adiponectin inhibits leptin signalling via multiple mechanisms to exert protective effects against hepatic fibrosis. Biochem J 440(3):385-395. doi:10.1042/BJ20102148

9. Marra F, Bertolani C (2009) Adipokines in liver diseases. Hepatology 50(3):957-969. doi:10.1002/hep. 23046

10. Wree A, Broderick L, Canbay A, Hoffman HM, Feldstein AE (2013) From NAFLD to NASH to cirrhosis-new insights into disease mechanisms. Nat Rev Gastroenterol Hepatol 10:627636. doi:nrgastro.2013.149 [pii] 10.1038/nrgastro.2013.149

11. Loomba R, Sanyal AJ (2013) The global NAFLD epidemic. Nat Rev Gastroenterol Hepatol 10(11):686-690. doi:10.1038/nrgastro.2013.171

12. Kisseleva T, Cong M, Paik Y, Scholten D, Jiang C, Benner C, Iwaisako K, Moore-Morris T, Scott B, Tsukamoto H, Evans SM, Dillmann W, Glass CK, Brenner DA (2012) Myofibroblasts revert to an inactive phenotype during regression of liver fibrosis. Proc Natl Acad Sci U S A 109:9448-9453. doi:1201840109 [pii] 10.1073/pnas.1201840109

13. Troeger JS, Mederacke I, Gwak GY, Dapito DH, Mu X, Hsu CC, Pradere JP, Friedman RA, Schwabe RF (2012) Deactivation of hepatic stellate cells during liver fibrosis resolution in mice. Gastroenterology 143(4):1073-1083 e1022. doi:S0016-5085(12)00925-0 [pii] 10.1053/j.gastro.2012.06.036

14. Friedman SL (2012) Fibrogenic cell reversion underlies fibrosis regression in liver. Proc Natl Acad Sci U S A 109(24):9230-9231. doi:10.1073/pnas.1206645109

15. Iredale JP, Benyon RC, Pickering J, McCullen M, Northrop M, Pawley S, Hovell C, Arthur MJ (1998) Mechanisms of spontaneous resolution of rat liver fibrosis. Hepatic stellate cell apoptosis and reduced hepatic expression of metalloproteinase inhibitors. J Clin Invest 102(3):538-549

16. Choi AM, Ryter SW, Levine B (2013) Autophagy in human health and disease. N Engl J Med 368(7):651-662. doi:10.1056/NEJMra1205406

17. Singh R, Kaushik S, Wang Y, Xiang Y, Novak I, Komatsu M, Tanaka K, Cuervo AM, Czaja MJ (2009) Autophagy regulates lipid metabolism. Nature 458(7242):1131-1135. doi:nature07976 [pii] 10.1038/nature07976

18. Hernandez-Gea V, Ghiassi-Nejad Z, Rozenfeld R, Gordon R, Fiel MI, Yue Z, Czaja MJ, Friedman SL (2012) Autophagy releases lipid that promotes fibrogenesis by activated hepatic stellate cells in mice and in human tissues. Gastroenterology 142(4):938-946. doi:S00165085(12)00012-1 [pii] 10.1053/j.gastro.2011.12.044

19. Puche JE, Lee YA, Jiao J, Aloman C, Fiel MI, Munoz U, Kraus T, Lee T, Yee HF Jr, Friedman SL (2013) A novel murine model to deplete hepatic stellate cells uncovers their role in amplifying liver damage in mice. Hepatology 57(1):339-350. doi:10.1002/hep.26053 
20. Marcellin P, Gane E, Buti M, Afdhal N, Sievert W, Jacobson IM, Washington MK, Germanidis G, Flaherty JF, Schall RA, Bornstein JD, Kitrinos KM, Subramanian GM, McHutchison JG, Heathcote EJ (2013) Regression of cirrhosis during treatment with tenofovir disoproxil fumarate for chronic hepatitis B: a 5-year open-label follow-up study. Lancet 381(9865):468_ 475. doi:10.1016/S0140-6736(12)61425-1

21. D’Ambrosio R, Aghemo A, Rumi MG, Ronchi G, Donato MF, Paradis V, Colombo M, Bedossa P (2012) A morphometric and immunohistochemical study to assess the benefit of a sustained virological response in hepatitis $\mathrm{C}$ virus patients with cirrhosis. Hepatology 56(2):532-543. doi:10.1002/hep.25606

22. Ramachandran P, Pellicoro A, Vernon MA, Boulter L, Aucott RL, Ali A, Hartland SN, Snowdon VK, Cappon A, Gordon-Walker TT, Williams MJ, Dunbar DR, Manning JR, van Rooijen N, Fallowfield JA, Forbes SJ, Iredale JP (2012) Differential Ly-6C expression identifies the recruited macrophage phenotype, which orchestrates the regression of murine liver fibrosis. Proc Natl Acad Sci U S A 109(46):E3186-E3195. doi:1119964109 [pii] 10.1073/ pnas.1119964109

23. Jiao J, Sastre D, Fiel MI, Lee UE, Ghiassi-Nejad Z, Ginhoux F, Vivier E, Friedman SL, Merad M, Aloman C (2012) Dendritic cell regulation of carbon tetrachloride-induced murine liver fibrosis regression. Hepatology 55(1):244-255. doi:10.1002/hep.24621

24. Snowdon VK, Fallowfield JA (2011) Models and mechanisms of fibrosis resolution. Alcohol Clin Exp Res 35(5):794-799. doi:10.1111/j.1530-0277.2010.01400.x

25. Liang TJ, Ghany MG (2014) Therapy of hepatitis C-back to the future. N Engl J Med 370(21):2043-2047. doi:10.1056/NEJMe1403619

26. Pawlotsky JM (2014) New hepatitis C virus (HCV) drugs and the hope for a cure: concepts in anti-HCV drug development. Semin Liver Dis 34(1):22-29. doi:10.1055/s-0034-1371007

27. Dudley JT, Sirota M, Shenoy M, Pai RK, Roedder S, Chiang AP, Morgan AA, Sarwal MM, Pasricha PJ, Butte AJ (2011) Computational repositioning of the anticonvulsant topiramate for inflammatory bowel disease. Sci Transl Med 3(96):96ra76. doi:10.1126/scitranslmed.3002648

28. O'Connell OJ, Kennedy MP, Henry MT (2011) Idiopathic pulmonary fibrosis: treatment update. Adv Ther 28(11):986-999. doi:10.1007/s12325-011-0066-5

29. Wynn TA (2011) Integrating mechanisms of pulmonary fibrosis. J Exp Med 208(7):1339_ 1350. doi:jem.20110551 [pii] 10.1084/jem.20110551

30. Mehal WZ, Iredale J, Friedman SL (2011) Scraping fibrosis: expressway to the core of fibrosis. Nat Med 17(5):552-553. doi:nm0511-552 [pii] 10.1038/nm0511-552

31. Henderson NC, Arnold TD, Katamura Y, Giacomini MM, Rodriguez JD, McCarty JH, Pellicoro A, Raschperger E, Betsholtz C, Ruminski PG, Griggs DW, Prinsen MJ, Maher JJ, Iredale JP, Lacy-Hulbert A, Adams RH, Sheppard D (2013) Targeting of alphav integrin identifies a core molecular pathway that regulates fibrosis in several organs. Nat Med 19(12):1617-1624. doi:10.1038/nm.3282

32. Zhu J, Choi WS, McCoy JG, Negri A, Zhu J, Naini S, Li J, Shen M, Huang W, Bougie D, Rasmussen M, Aster R, Thomas CJ, Filizola M, Springer TA, Coller BS (2012) Structureguided design of a high-affinity platelet integrin alphaIIbbeta3 receptor antagonist that disrupts $\operatorname{Mg}(2)(+)$ binding to the MIDAS. Sci Transl Med 4(125):125ra132. doi:10.1126/ scitranslmed.3003576

33. Hellerbrand C (2014) Molecular targets for antifibrotic therapy in liver disease: using magic bullets for crossfire rather than a one-sided shotgun attack. Gut 63(7):1039-1041. doi:10.1136/ gutjnl-2013-305908

34. Schuppan D, Kim YO (2013) Evolving therapies for liver fibrosis. J Clin Invest 123(5):18871901. doi:10.1172/JCI66028

35. Cohen-Naftaly M, Friedman SL (2011) Current status of novel antifibrotic therapies in patients with chronic liver disease. Ther Adv Gastroenterol 4(6):391-417. doi:10.1177/17562 83X11413002 10.1177_1756283X11413002 [pii] 